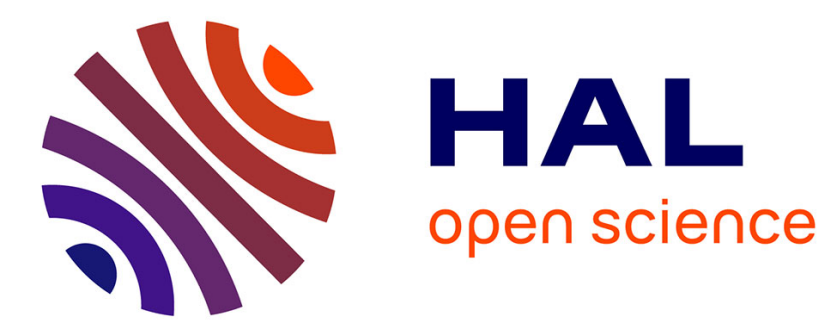

\title{
Cryogel-Integrated Biochip for Liver Tissue Engineering
} Lilandra Boulais, Rachid Jellali, Ulysse Pereira, Eric Leclerc, Sidi A Bencherif, C. Legallais

\section{To cite this version:}

Lilandra Boulais, Rachid Jellali, Ulysse Pereira, Eric Leclerc, Sidi A Bencherif, et al.. CryogelIntegrated Biochip for Liver Tissue Engineering. ACS Applied Bio Materials, 2021, 4 (7), pp.56175626. 10.1021/acsabm.1c00425 . hal-03322953

\section{HAL Id: hal-03322953 https://hal.science/hal-03322953}

Submitted on 20 Aug 2021

HAL is a multi-disciplinary open access archive for the deposit and dissemination of scientific research documents, whether they are published or not. The documents may come from teaching and research institutions in France or abroad, or from public or private research centers.
L'archive ouverte pluridisciplinaire HAL, est destinée au dépôt et à la diffusion de documents scientifiques de niveau recherche, publiés ou non, émanant des établissements d'enseignement et de recherche français ou étrangers, des laboratoires publics ou privés. 


\section{Cryogel-integrated Biochip for Liver Tissue Engineering}

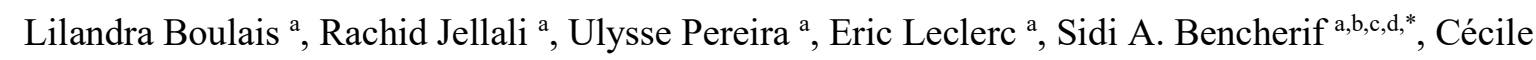
Legallais ${ }^{a, *}$

a Université de Technologie de Compiègne, UMR CNRS 7338 Biomécanique et Bioingénierie, Centre de Recherche de Royallieu, Compiègne, France

${ }^{\mathrm{b}}$ Department of Chemical Engineering, Northeastern University, Boston, MA, USA

${ }^{\mathrm{c}}$ Department of Bioengineering, Northeastern University, Boston, MA, USA

${ }^{\mathrm{d}}$ Harvard John A. Paulson School of Engineering and Applied Sciences, Harvard University, Cambridge, MA 02138, USA

E-mail addresses: lilandra.boulais@utc.fr, rachid.jellali@utc.fr, ullysse.pereira@utc.fr, eric.leclerc@utc.fr, s.bencherif@northeastern.edu, cecile.legallais@utc.fr

\section{*Corresponding authors:}

Cécile Legallais, cecile.legallais@utc.fr, +33344234423

Université de technologie de Compiègne, UMR CNRS 7338 Biomechanics \& Bioengineering, Rue du Dr Schweitzer, 60203 Compiègne, France

Sidi A. Bencherif, s.bencherif@northeastern.edu, +1 6173737103

Northeastern University, 360 Huntington Avenue, 336 Mugar Life Sciences Building, Boston, MA 02115, USA 


\begin{abstract}
Microfluidic systems and polymer hydrogels have been widely developed for tissue engineering. Yet only a few tools combining both approaches, especially for in vitro liver models, are being explored. In this study, an alginate-based cryogel-integrated biochip was engineered for dynamic hepatoma cell line culture in three dimensions (3D). The alginate cryogel was covalently cross-linked in the biochip at subzero temperatures $\left(\mathrm{T}<0{ }^{\circ} \mathrm{C}\right)$ to create a scaffold with high mechanical stability and an interconnected macroporous network. By varying the alginate concentration and the cross-linker ratio, the Young's modulus of the cryogel can be fine-tuned between 1.5 and $29 \mathrm{kPa}$, corresponding to the range of stiffness of the different physiological states of the liver. We demonstrated that HepG2/C $3 \mathrm{~A}$ cells can be cultured and maintained viable under dynamic conditions in this device up to 6 days. Albumin synthesis and glucose consumption increased over the cell culture days. Moreover, a 3D cell structure was observed across the entire height of the biochip, which was preserved following alginate lyase treatment to remove the cryogel-based scaffold. In summary, these results represent a proof of concept of an interesting new cell culture technology that should be further investigated to engineer healthy and cirrhotic liver models.
\end{abstract}

Keywords: alginate, cryogel, biochip, hepatocytes, liver tissue engineering 
Graphical abstract

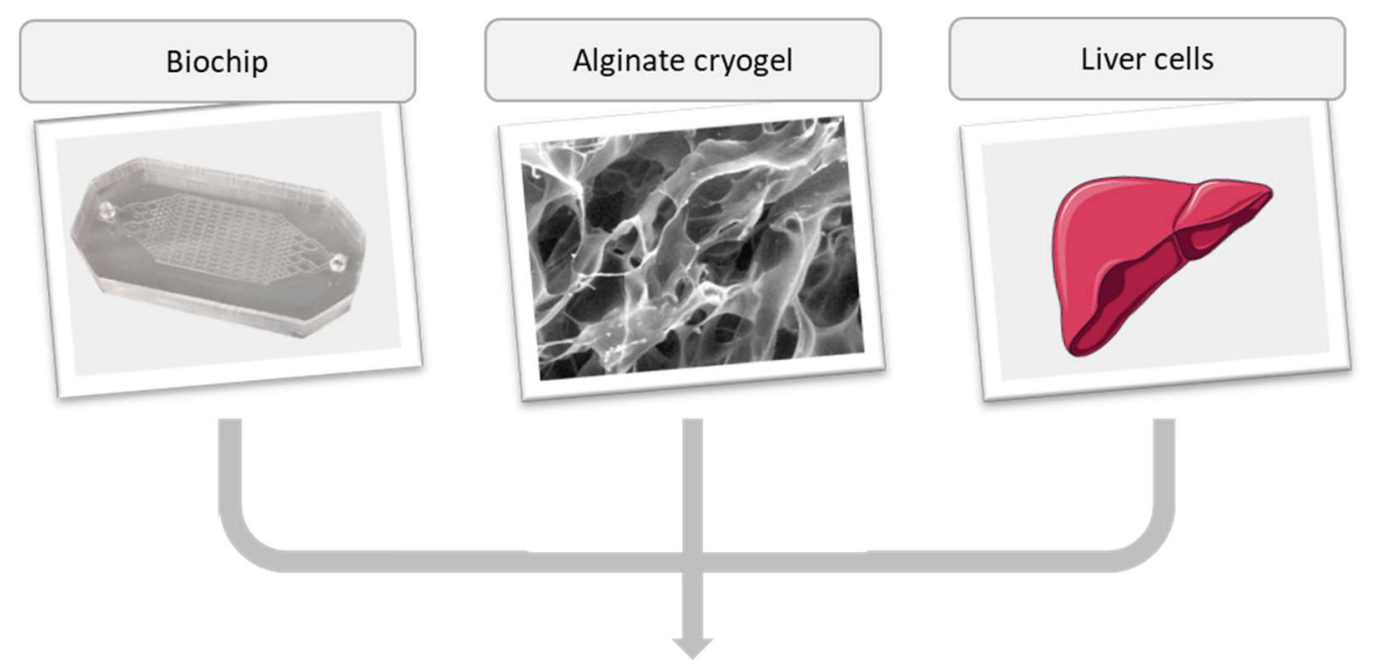

Cryogel-integrated biochip for

liver tissue engineering 


\section{Introduction}

Developing in vitro liver models remains a major challenge for the pharmaceutical industry. Current in vitro and animal models do not faithfully reproduce the behavior and functions of hepatic cells in their native environment. Preclinical studies of the drug development process are therefore limited, and the results are sometimes unreliable. This leads to late interruption of drug development: among the new experimental drugs that enter Phase I and Phase II clinical trials, 52\% and $71 \%$, respectively, fail to transition in the next stage of development [1]. The main causes have been associated with safety and efficacy, which are not always identified through in vitro and preclinical studies [2]. Advanced cell culture tools are thus still critically needed.

A widely accepted method for enhancing in vitro assays, with improved reliability, is to culture mammalian cells in an environment that emulates their in vivo conditions. For instance, the liver is a highly perfused organ with a complex microstructure, both of which are key parameters for regulating a range of cellular behaviors and functions [3]. To that end, liver tissue reconstruction should recapitulate both a complex and perfusable cellular structure in 3D. In recent years, two main approaches have been extensively investigated to engineer new tissues: the development of microfluidic systems, and the design of advanced 3D scaffolds [4-9]. Both techniques have shown a number of advantages, including creating native-like synthetic microenvironments for in vitro cell culture.

On the one hand, microfluidic systems have been used as miniaturized bioreactors, in continuous perfusion, facilitating oxygen and nutrient supply, but also metabolic waste removal. These microfluidic systems, also known as biochips or biochips, are primarily made of polydimethylsiloxane (PDMS), which is transparent, and permeable to gaz. Due to tremendous technological innovation in biochip design, their internal surfaces can be patterned to mimic aspects of the native environment. In pharmaceutical and toxicological studies, liver-on-a-chip systems are considered a promising tool for reducing or bypassing animal testing. Several studies have shown improved viability and function of hepatocytes in perfusion compared to classic static culture and a correlation between in vitro and in vivo toxicity data $[10,11]$. However, the cellular organization is usually that of spheroids or layers covering surfaces, the size of the tissue-like structures is therefore limited by cell culture medium diffusion within. 
On the other hand, 3D scaffolds have been designed as artificial extracellular matrices for tissue engineering. Of them, hydrogels are cross-linked hydrophilic polymeric networks capable of absorbing large amounts of water or biological fluids. Hydrogel scaffolds are non-toxic and have been widely used for soft tissue reconstruction [12-24]. However, hydrogels are typically mesoporous, leading to an unfavorable microenvironment that entraps and constrains encapsulated cells, and ultimately preventing their cellular organization in $3 \mathrm{D}$. To overcome this challenge, cross-linking polymers at subzero temperatures $\left(\mathrm{T}<0{ }^{\circ} \mathrm{C}\right)$, a mechanism known as cryopolymerization, has been developed, making it possible to manufacture ice-templated cryogels [25-35]. This subset of hydrogels has remarkable and tunable properties, including an interconnected and macroporous network [36-41]. Due to their unique microarchitectural features, cryogels allow homogenous cell seeding throughout the entire 3D construct. Additionally, cryogels can support tissue growth as they make the diffusion of oxygen and nutrients possible, as well as the removal of waste products, and present sufficient space for cell proliferation and organization [42-44]. Cryogels can be fabricated either ionically or covalently, the latter being widely used as it ensures more stability and tunable mechanical properties [45]. This is of utmost importance, as the elastic properties of the liver depend on its physiological state: healthy tissue is relatively soft ( $4 \mathrm{kPa})$, whereas cirrhotic tissue is associated with greater stiffness $(\sim 15 \mathrm{kPa})$.

In this study, we investigated the potential of a new method of performing $3 \mathrm{D}$ cell cultures in microfluidic devices instead of the common 3D spheroid culture: a macroporous cryogel-integrated biochip with tunable mechanical properties intended to mimic the stiffness of a healthy or pathological liver tissue (Fig. 1). We engineered a covalently cross-linked cryogel made of alginate, a polysaccharide derived from brown algae, which has been used extensively to develop hydrogel due to its cytocompatibility and biocompatibility $[46,47]$. Next, the alginate cryogel was characterized at the macroscopic and microscopic levels, followed by hydrodynamic characterization of the device. Lastly, cell culture validation was performed using HepG2/C3A cells, a commonly used human hepatic cell line. 


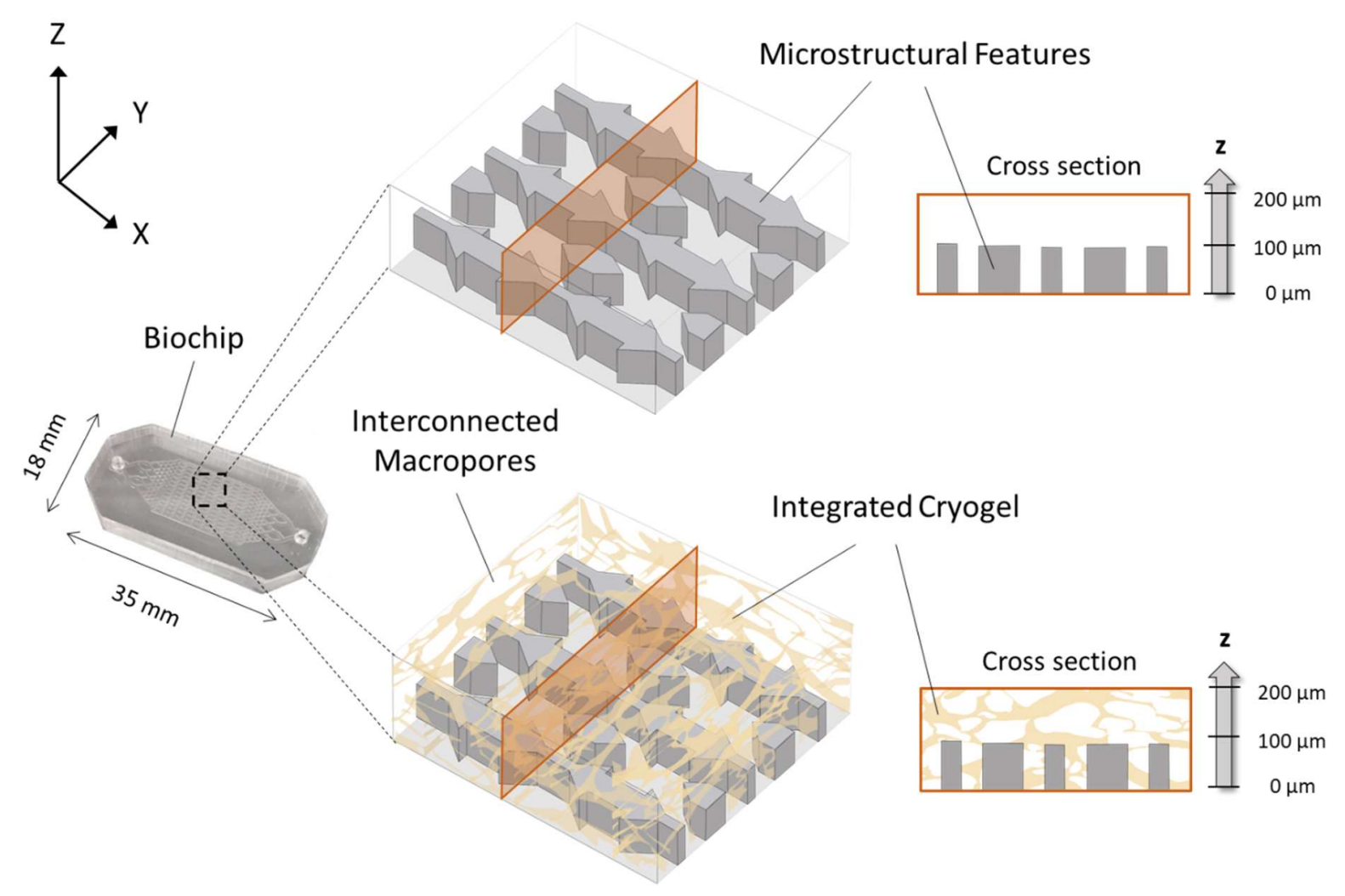

Fig. 1. Cryogel-free and cryogel-integrated microfluidic devices. Photo of a biochip system (left), schematics depicting the internal microstructural features of the device (middle), and cross-sectional views (right).

\section{Materials and methods}

2.1. Cryogel manufacturing and characterization

\subsubsection{Cylindrical samples}

Alginate solution was prepared by dissolving alginate (Alginate Manucol LKX, FMC Biopolymer) at a (G/M) ratio of (30-40/60-70) in a $50 \mathrm{mM}$ 2-(N-Morpholino) ethanesulfonic acid (MES) solution (SigmaAldrich) at $1 \%$ or $2 \%(\mathrm{w} / \mathrm{v})$. To prepare $1 \mathrm{~mL}$ of alginate solution, $12 \mu \mathrm{L}$ of adipic acid dihydrazide (AAD) (Sigma-Aldrich) solution at $100 \mathrm{mg} / \mathrm{mL}$ in MES was first added, then $27 \mu \mathrm{L}$ of $\mathrm{N}-(3-$ Dimethylaminopropyl)-N'-ethylcarbodiimide hydrochloride (EDC) (Sigma-Aldrich) solution at 100 $\mathrm{mg} / \mathrm{mL}$ in MES for a solution at $1 \%$ alginate for a AAD:EDC ratio of $(1: 1)$. Samples with a ratio of $(1: 2)$ and (1:3) were also prepared. After mixing, the final solution was placed in cylindrical Teflon molds ( 8 $\mathrm{mm}$ diameter, $6 \mathrm{~mm}$ height) which were immediately incubated overnight at different subzero 
temperatures, $-20^{\circ} \mathrm{C},-50{ }^{\circ} \mathrm{C}$, and $-80{ }^{\circ} \mathrm{C}$. After thawing, the cylindrical alginate cryogels were washed with deionized water. The samples were then incubated in a solution of sodium bicarbonate at $0.1 \mathrm{mM}$ for 20 min and finally washed with deionized water.

\subsubsection{Mechanical properties}

Cylindrical alginate cryogel samples $(8 \mathrm{~mm}$ diameter, $6 \mathrm{~mm}$ height) were prepared to measure the Young's modulus (Y) using a mechanical testing system (Synergie 400, MTS system) with a $2 \mathrm{~N}$ load cell. Before testing, the samples were incubated overnight in phosphate buffered saline (PBS) at $37^{\circ} \mathrm{C}$. The measurements were done in PBS at a compression rate of $3 \mathrm{~mm} / \mathrm{min}$ up to $50 \%$ of deformation.

\subsubsection{Degree of pore connectivity and swelling ratio}

Cylindrical alginate-based cryogel samples ( $8 \mathrm{~mm}$ diameter, $6 \mathrm{~mm}$ height) were used to measure the degree of pore connectivity (DC) and the swelling ratio $\left(\mathrm{Q}_{\mathrm{M}}\right)$, following previously published protocols [33].

$\mathrm{DC}=\left(\mathrm{m}_{\mathrm{h}}-\mathrm{m}_{\mathrm{d}}\right) / \mathrm{m}_{\mathrm{h}} \times 100 \%$

$\mathrm{Q}_{\mathrm{M}}=\left(\mathrm{m}_{\mathrm{h}}-\mathrm{m}_{\mathrm{l}}\right) / \mathrm{m}_{1}$

With $\mathrm{m}_{\mathrm{h}}$ : weight of hydrated sample in PBS overnight at $37^{\circ} \mathrm{C}$

$\mathrm{m}_{\mathrm{d}}$ : dehydrated weight after wicking on absorbent paper

$\mathrm{m}_{1}$ : dried weight after lyophilization

\subsubsection{Morphological observation and porosity analysis}

Cylindrical alginate cryogels were lyophilized (Alpha 1-2 LDplus, CHRIST) and then gold-coated by vacuum deposition. The samples were then imaged using scanning electron microscopy (SEM) (XL 30ESEM FEG, Philips, The Netherlands). The pore size was measured using the software ImageJ, and a total of 4 images across 4 samples were analyzed with 10 different measures of pore size per image.

2.2. Biochip fabrication and characterization 


\subsubsection{Microfluidic device fabrication}

The fabrication of PDMS biochips has been previously reported [48,49]. Briefly, the biochip is composed of two PDMS (SYLGARD 184 kit, Dow Corning) layers manufactured using the replica molding process. The two layers are then sealed by reactive air plasma treatment (plasma cleaner, Harrick Plasma). The microstructures of the bottom layer contain several tissue chambers connected with microchannels. The top layer, with a reservoir (depth of $100 \mu \mathrm{m}$ ), includes an inlet and outlet for culture medium perfusion. The total resulting volume of the assembled cell culture chamber is $40 \mu \mathrm{L}$.

\subsubsection{Alginate cryogel synthesis in biochips}

Alginate solution was prepared by dissolving alginate in a $50 \mathrm{mM}$ MES solution at $1 \%(\mathrm{w} / \mathrm{v})$. For $1 \mathrm{~mL}$ of alginate solution, $12 \mu \mathrm{L}$ of a stock solution of AAD at $100 \mathrm{mg} / \mathrm{mL}$ in MES was added, and then 27 $\mu \mathrm{L}$ of a stock solution of EDC solution at $100 \mathrm{mg} / \mathrm{mL}$ in MES was finally incorporated. After mixing, the final solution was injected into the biochip with a syringe. The biochip was immediately placed in a freezer overnight at $-20^{\circ} \mathrm{C}$. After thawing, the alginate cryogel-integrated biochip was washed with deionized water. The device was incubated with a solution of sodium bicarbonate at $0.1 \mathrm{mM}$ for $20 \mathrm{~min}$ and then washed with deionized water.

\subsubsection{Hydrodynamic characterization}

To characterize the pressure drop under flow conditions caused by the additional resistance inherent to the cryogel construct inside the biochip, a pressure controller (MFCS ${ }^{\mathrm{TM}}$-EZ, Fluigent) and a flowmeter (Flow Unit type M model, Fluigent) were used. A target flow was imposed at the exit of the biochip and the pressure required at the entrance of the biochip to obtain this flow was recorded. As the biochip's outlet was under atmospheric pressure, that pressure drop was equal to the recorded inlet pressure.

\subsubsection{Alginate cryogel observation}

After cross-linking inside the biochip, the cryogel was functionalized with aminofluorescein (Sigma). For $1 \mathrm{~mL}$ of $50 \mathrm{mM}$ MES solution, $12 \mu \mathrm{L}$ of a stock solution of $1 \mathrm{mM}$ aminofluorescein and $27 \mu \mathrm{L}$ of a 
stock solution of EDC solution at $100 \mathrm{mg} / \mathrm{mL}$ in MES were mixed and injected into the alginate cryogelintegrated biochips. After $24 \mathrm{~h}$ incubation, the samples were then washed thoroughly with PBS and subsequently imaged by confocal microscopy (Zeiss LSM 710).

\subsection{Cell culture}

\subsubsection{Cell and culture medium}

The hepatocellular carcinoma-derived cell line HepG2/C3A (ATCC, reference CRL-10741) was used as a liver cell model. The cell culture medium consisted of Minimum Essential Medium (MEM, Gibco) supplemented with 10\% fetal bovine serum (FBS, Gibco), 2 mM L-Glutamine (PAN BIOTECH), 0.1 $\mathrm{mM}$ nonessential amino acids (Gibco), $1 \mathrm{mM}$ sodium pyruvate (Gibco), 1\% HEPES buffer (PAN BIOTECH) and 100 units $/ \mathrm{mL}$ of penicillin-streptomycin (PAN BIOTECH). Maintenance of $\mathrm{HepG} 2 / \mathrm{C} 3 \mathrm{~A}$ cells was performed in $75 \mathrm{~cm}^{2}$ flasks at $37^{\circ} \mathrm{C}$ in $5 \% \mathrm{CO}_{2}$ incubator. The cells were passaged weekly at nearly full confluence and the medium was replaced every 2 days.

\subsubsection{Cell culture in alginate cryogel-integrated biochip}

Prior to cell seeding, the alginate cryogel-integrated biochips were sanitized using $70 \%$ ethanol for 15 min. After washing with PBS, the alginate cryogel was subsequently coated with a $0.3 \mathrm{mg} / \mathrm{mL}$ collagen solution (Collagen type 1 rat tail, Corning Life Science) for $2 \mathrm{~h}$ at $37{ }^{\circ} \mathrm{C}$. The cells were seeded at a density of $5 \times 10^{5}$ cells / biochip and incubated for $24 \mathrm{~h}$ in a $5 \% \mathrm{CO}_{2}$ incubator at $37^{\circ} \mathrm{C}$. Then, the biochips were placed in the Integrated Dynamic Cell Cultures in Microsystems (IDCCM) device, a fluidic platform making possible the parallelized culture of 12 independent biochips $[49,50]$. Each biochip was connected to two adjacent wells with a volume of $2 \mathrm{~mL}$ per well (Fig. 2A). The perfusion was controlled by peristaltic pump connected to the cover of the IDCCM device with polytetrafluoroethylene (PTFE) tubes. The experiment was performed at $10 \mu \mathrm{l} / \mathrm{min}$ for 7 days $(1$ day static culture and 6 days dynamic culture) and the culture medium was changed every 2 days in the individual wells (Fig. 2B). 


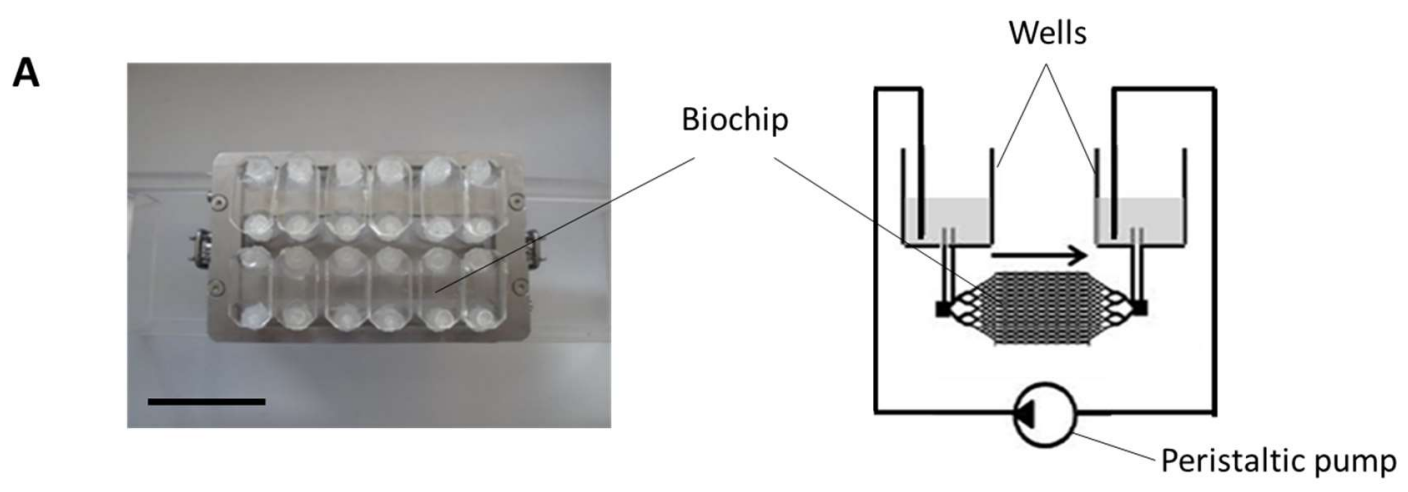

B

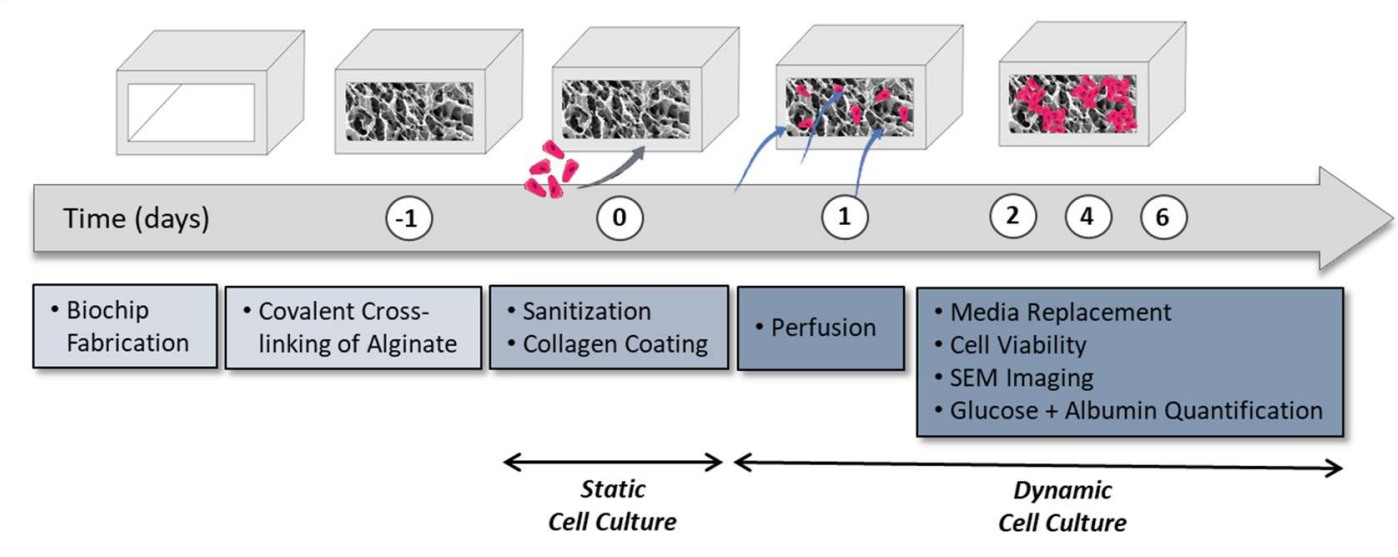

Fig. 2. Microfluidic setup and experimental steps. (A) Bottom view of the Integrated Dynamic Cell Cultures in Microsystems (IDCCM) device (left), and schematic representation of the microfluidic circuit of one individual biochip (right), Scale bar $=50 \mathrm{~mm}$. (B) Chronological experimental steps of hepatic cell culture in the alginate cryogel-integrated biochip.

\subsubsection{Cell viability assay}

Cell viability was assessed at day 2, 4 and 6. The biochips were first washed with PBS and then incubated with a Via Quant ${ }^{\mathrm{TM}}$ Far-Red Fixable Dead Cell Stain Kit (GeneCopoeia) for $30 \mathrm{~min}$ at room temperature (RT). After washing with PBS, the samples were fixed in 4\% paraformaldehyde (PFA, VWR) for 10 $\min$ at RT. The samples were then permeabilized with a $0.1 \%$ TritonX-100 solution for 5 min and blocked with a $1 \%$ Bovine Serum Albumin (Sigma) for $30 \mathrm{~min}$. Actin and nuclei staining of cells were performed using Alexa Fluor 488 Phalloidin (1/1000, Thermofisher) and DAPI (1/200, Sigma). Finally, the samples were washed with PBS before imaging by confocal microscopy (Zeiss LSM 710). Confocal images were analyzed using ImageJ software to assess cell viability. 


\subsubsection{SEM imaging}

Following cell fixation in $4 \%$ PFA and washing with PBS, small slices of biochip were cut with a scalpel and their transverse views were imaged by SEM (XL 30-ESEM FEG, Philips, The Netherlands).

\subsubsection{Cell function}

Albumin production and glucose consumption were measured in the culture medium recovered at days 2, 4 and 6. The protocols have been previously described [48]. Albumin was quantified using an ELISA sandwich technique (Human Albumin ELISA kit, Bethyl Laboratories) and the glucose was quantified by enzyme-mediated reactions using a chemistry analyzer (INDIKO, ThermoFisher).

\subsubsection{Alginate lyase}

To remove the alginate cryogel, a solution of alginate lyase (Sigma) diluted at $10 \mathrm{mg} / \mathrm{mL}$ in cell culture medium was injected in the microfluidic devices. The systems were then placed in the incubator at 37 ${ }^{\circ} \mathrm{C}$ for $1 \mathrm{~h}$ under perfusion at $10 \mu \mathrm{L} / \mathrm{min}$. After breaking down of the alginate cryogel, the solution was replaced by cell culture medium.

\subsection{Statistics}

Data are shown as mean \pm standard deviations (SD). To determine significant statistical differences the one-way or two-way ANOVA tests were used. P-values $<0.05$ were considered statistically significant.

\section{Results}

\subsection{Alginate cryogel characterization}

First, we chose to perform all the characterizations on cylindrical samples of alginate cryogels. In fact, after implementation in the biochip, some of the scaffold's properties were more challenging to evaluate. The effects of three main parameters on cryogel properties were studied: temperature of polymerization, alginate concentration, and cross-linking ratio. The aim was to understand the impact of the changes 
across these different parameters on the biomaterial's properties, and to select the best conditions for cell culture in the biochip device.

Cryopolymerization allows macroporous scaffolds to be created, the pore size of which depends on ice crystal size, which in turn depends on temperature. Therefore, the choice of the latter is important and must be defined. First, cylindrical samples of $1 \%(\mathrm{w} / \mathrm{v})(\mathrm{AAD}: \mathrm{EDC}=1: 1)$ alginate cryogels were obtained after covalent cross-linking performed at subzero temperatures. Three different cryopolymerization temperatures were tested: $-20^{\circ} \mathrm{C},-50^{\circ} \mathrm{C}$, and $-80{ }^{\circ} \mathrm{C}$. After cryopolymerization, the resulting cryogel constructs were thawed at RT. The cylindrical shape was not maintained for the temperatures at $-50{ }^{\circ} \mathrm{C}$ and $-80{ }^{\circ} \mathrm{C}$ as the samples collapsed under their weight (Fig. 3A). However, for the cryogels manufactured at $-20^{\circ} \mathrm{C}$, the alginate cylinders were able to maintain their cylindrical shape. The freezing temperature $-20{ }^{\circ} \mathrm{C}$ was thus selected for the next steps of this study.

Like hydrogels, cryogels can be characterized for their ability to absorb fluid, an essential criterion for further cell culture applications. Fig. 3B and $\mathrm{C}$ show the swelling ratio (i.e., $\mathrm{Q}_{\mathrm{M}}$ ) and the degree of pore connectivity of cryogels made with different alginate concentrations and cross-linker agent AAD:EDC at various ratios. Alginate cryogel $(1 \%(\mathrm{w} / \mathrm{v})(1: 1))$ exhibits a $\mathrm{Q}_{\mathrm{M}}$ of 133 , which is significantly higher than 97 obtained for 2\% (w/v) (2:2) alginate cryogel (Fig. 3B). Similarly, 1\% (w/v) (1:1) alginate cryogel has a higher $\mathrm{Q}_{\mathrm{M}}$ than 1\% (w/v) (1:2) and (1:3) alginate cryogel, 133 vs 107 and 81, respectively. Moreover, $1 \%(\mathrm{w} / \mathrm{v})(1: 1)$ alginate cryogel samples were characterized with a higher degree of pore connectivity, DC $=92 \%$ vs. $70 \%$ for $2 \%(w / v)(2: 2)$ alginate cryogel (Fig. 3C). DC for $1 \%(w / v)(1: 2)$ and (1:3) alginate cryogels were $85 \%$ and $90 \%$, respectively. Therefore, increasing the alginate concentration and the AAD:EDC ratio decreased the fluid uptake of cryogel.

In order to get as close as possible to the liver's physiological microenvironment, alginate cryogel should exhibit mechanical properties similar to those of the liver. The mechanical properties of alginate cryogels were determined after compression tests by analyzing stress-strain curves. The resulting Y values are shown in Fig. 3D. Cryogel at 1\% (w/v) (1:1) displayed lower mechanical properties than 2\% (w/v) (2:2) cryogels, with a Y of $1.5 \pm 0.6 \mathrm{kPa} v s 6.8 \pm 2.4 \mathrm{kPa}$, respectively. Similarly, increasing the amount of cross-linking agent increased the $\mathrm{Y}$ with much more significance. The $1 \%(\mathrm{w} / \mathrm{v})(1: 2)$ cryogel had a Y of $16.4 \pm 4.1 \mathrm{kPa}$, over 10 times the value reported for cryogels formulated with $1 \%(\mathrm{w} / \mathrm{v})(1: 1)$ 
alginate. Cryogel at $1 \%(\mathrm{w} / \mathrm{v})(1: 3)$ was even stiffer, with a $\mathrm{Y}$ of $29.4 \pm 3.6 \mathrm{kPa}$. Therefore, increasing either alginate concentration or $\mathrm{AAD}: \mathrm{EDC}$ ratio resulted in increased alginate cryogel's mechanical properties. Moreover, the $\mathrm{Y}$ of alginate cryogels at $1 \%(\mathrm{w} / \mathrm{v})(1: 1)$ and $2 \%(\mathrm{w} / \mathrm{v})(2: 2)$ were similar to that of healthy liver tissue. However, alginate cryogel at $1 \%(w / v)(1: 2)$ exhibited mechanical properties in the range of a cirrhotic liver tissues, a pathological condition due to severe fibrosis in long-term liver disease. It should be noted that the alginate cryogel at $1 \%(\mathrm{w} / \mathrm{v})(1: 3)$ was too rigid to be compared to any hepatic tissues, healthy or impaired.

A

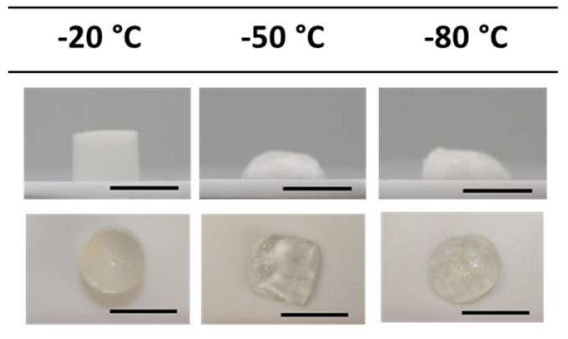

C

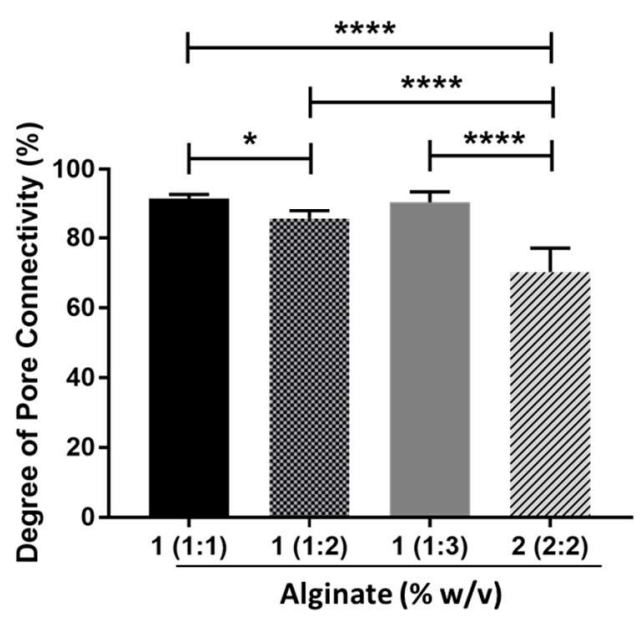

B

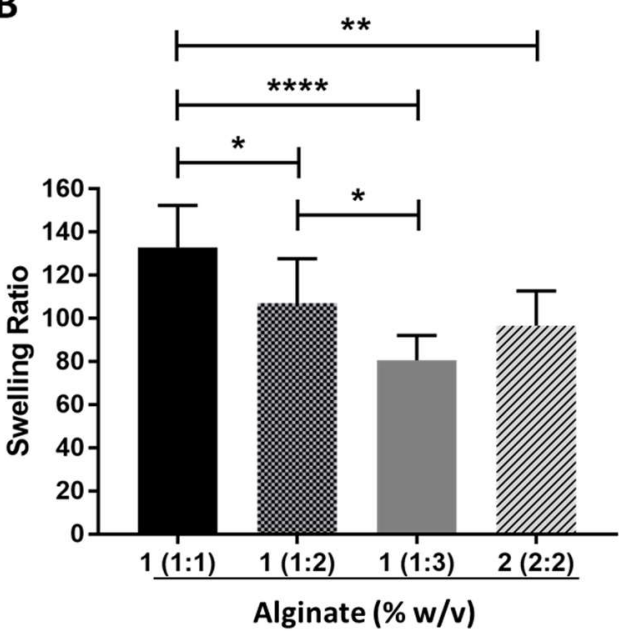

D

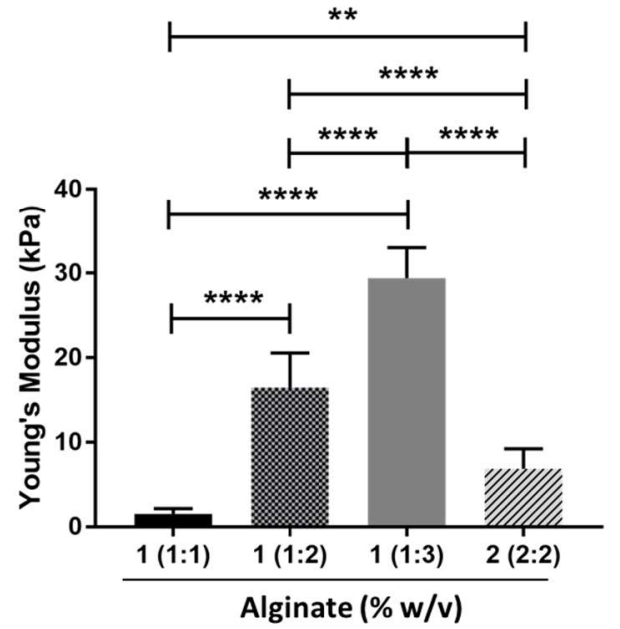

Fig. 3. Physical characterization of alginate cryogels. (A) Macroscopic observations (photographs) of cylindrical 1\% w/v (1:1) alginate-based cryogels fabricated at various subzero temperatures. Scale bar $=10 \mathrm{~mm}$. Physical properties of cryogels: (B) Swelling Ratio, (C) Degree of Pore Connectivity, and (D) Young's Modulus. (1:1), (1:2), (1:3) and (2:2) represent the AAD:EDC cross-linker ratio. Values 
represent mean and SD $(\mathrm{n}=8)$. Data were analyzed using one-way ANOVA: ${ }^{*} \mathrm{p}<0.05,{ }^{*} \mathrm{p}<0.01$, $* * * * \mathrm{p}<0.0001$.

The cryogels' microstructural features were characterized by SEM. Alginate cryogels at 1\% (w/v) (1:1) and 2\% (w/v) (2:2) showed a highly porous network with large and interconnected pores with irregular shapes (Fig. 4A). However, alginate cryogels at $1 \%(\mathrm{w} / \mathrm{v})(1: 2)$ and $(1: 3)$ exhibited a less porous structure. The pore size measured for alginate $1 \%(\mathrm{w} / \mathrm{v})(1: 1)$ and $2 \%(\mathrm{w} / \mathrm{v})(2: 2)$ ranged from 20 to 340 $\mu \mathrm{m}$ with a mean pore size of approximately $100 \mu \mathrm{m}$ for both (Fig. 4B). Based on our results, $1 \%(\mathrm{w} / \mathrm{v})$ $(1: 1)$ and $2 \%(\mathrm{w} / \mathrm{v})(2: 2)$ alginate cryogels were identified as the most promising candidates for performing cell culture due to their ability to uptake large amounts of fluids, exhibit a porous structure, and display suitable mechanical properties similar to those of healthy liver tissue. Therefore, these cryogels were used for the next steps in our experiments. 
A
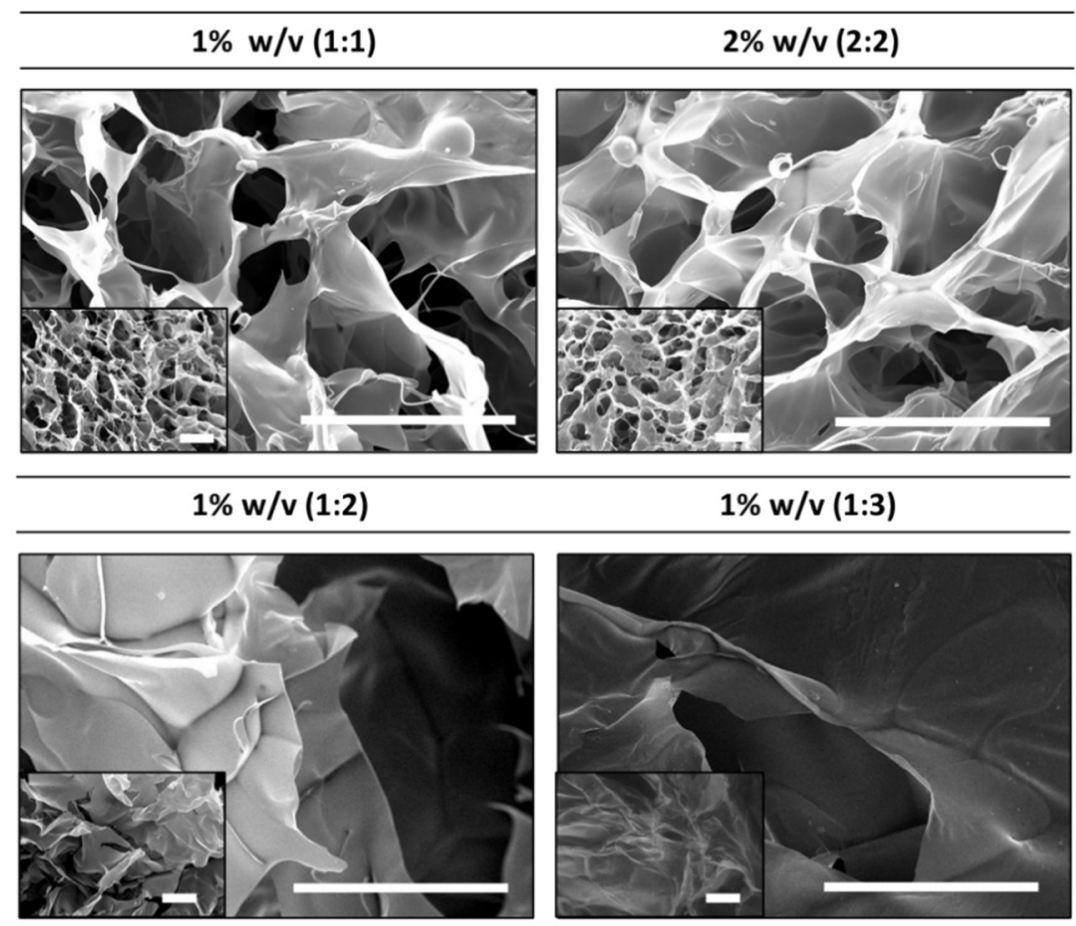

$1 \% \mathrm{w} / \mathrm{v}(1: 3)$

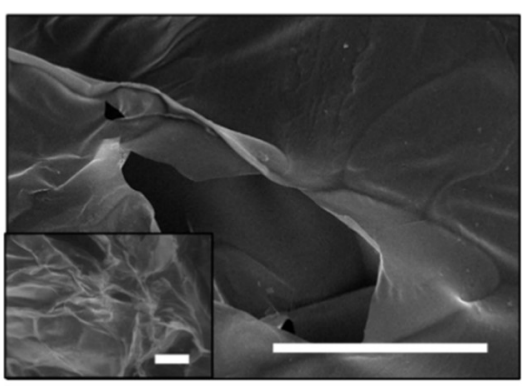

B
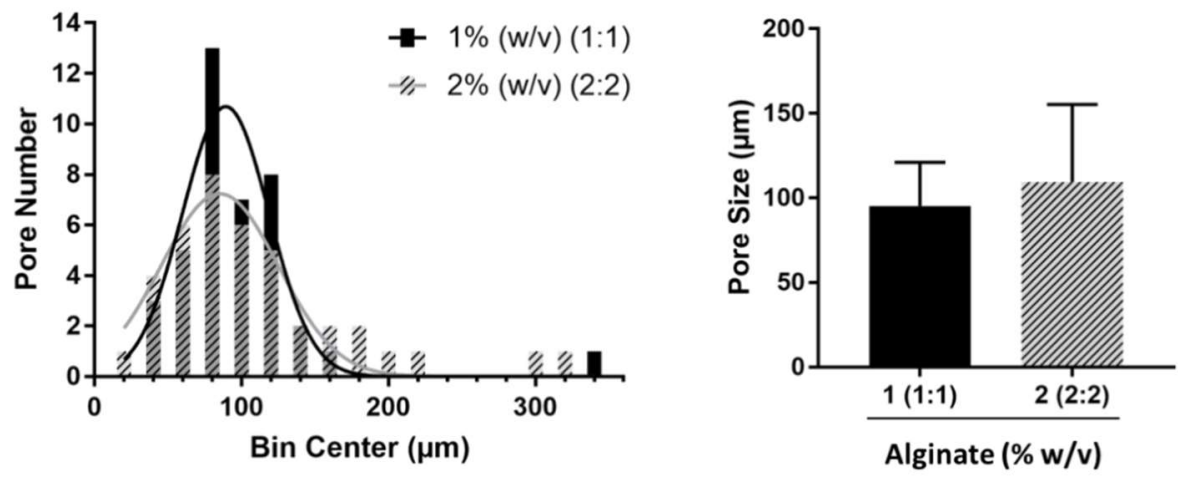

Fig. 4. Morphological characterization of alginate cryogels. (A) SEM images of alginate-based cryogels. Scale bar $=200 \mu \mathrm{m}$. (B) Pore size distribution (left) and average pore size (right) of alginatebased cryogels. (1:1), (1:2), (1:3) and (2:2) represent the AAD:EDC cross-linker ratio. Values represent mean and $\mathrm{SD}(\mathrm{n}=4,10$ pore sizes measured/SEM image).

\subsection{Alginate cryogel-integrated biochip}

Here, the feasibility of cross-linking alginate cryogels within a microfluidic device was investigated. After an injection step in the biochip, the process of cryopolymerization was performed. Fig. 5A shows cryogels integrated within the biochips. The 3D structure of the microfluidic device is visible and easily recognizable with its squares and arrows while the alginate cryogel is also easily visible, corresponding 
to the filaments. The cryogels were polymerized homogenously throughout the device, occupying all the available space, from the inlet to the outlet. However, it is difficult with this method to ensure whether the cryogel occupies the biochip from the bottom to the top of the device, including the space available between the microstructures.

In order to observe the alginate cryogel across the whole height of the biochip, alginate was tagged with aminofluorescein. The samples were then observed under confocal microscopy and stacks were performed from the bottom $(0 \mu \mathrm{m})$ to the top $(200 \mu \mathrm{m})$ of the biochip (Fig. $5 \mathrm{~B})$. From $0 \mu \mathrm{m}$ to $100 \mu \mathrm{m}$, corresponding to the lower face (microstructured), the porous structure of the alginate cryogel could be seen, ensuring its location between the microstructures of the biochip. From $100 \mu \mathrm{m}$ to $200 \mu \mathrm{m}$, corresponding to the upper face (not microstructured), the alginate cryogel was also present with a porous structure. Thus, the integrated cryogel occupied the entire height of the biochip, including the space between the microstructures, and retained a macroporous structure when fabricated inside the biochip.

To investigate the additional resistance to flow that might be induced by this structure filling the whole volume, the pressure applied at the entrance of the biochip to reach the target flow was measured (Fig. 5C). The flow rates ranging from 5 to $30 \mu \mathrm{L} / \mathrm{min}$ were relevant for cell culture [50],[51] and prevented any tear of the cryogel. The design of the biochip itself resulted in very poor resistance to flow. Darcy's law, which describes the flow of a fluid through a porous medium, was found to fit well with the experimental data (i.e., a linear regression as shown in Fig. 5C). The calculated slopes, proportional to the resistance, were 2.06, 1.74 and $1.18 \mathrm{mbar} / \mu \mathrm{L}$.min for $2 \%(\mathrm{w} / \mathrm{v})(2: 2)$ cryogel-integrated, $1 \%(\mathrm{w} / \mathrm{v})$ (1:1) cryogel-integrated, and cryogel-free biochips, respectively. Integrating the cryogel within the microfluidic device thus resulted in an increase in resistance to flow, which appeared to be proportional to the alginate concentration. However, this additional resistance was moderate, and the pressure remained within workable flow conditions that could be applied to cell culture conditions, i.e. 10 $\mu \mathrm{L} / \mathrm{min}$. As the additional resistance to flow was lower for $1 \%$ (w/v) (1:1) alginate cryogel, this condition was selected for cell culture. 
A

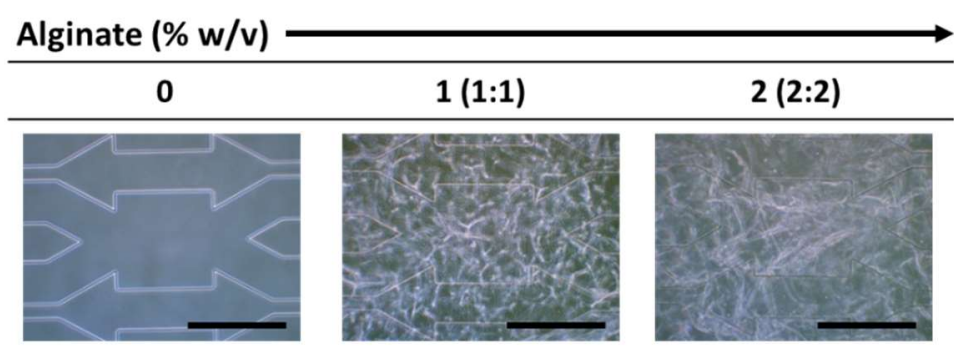

B
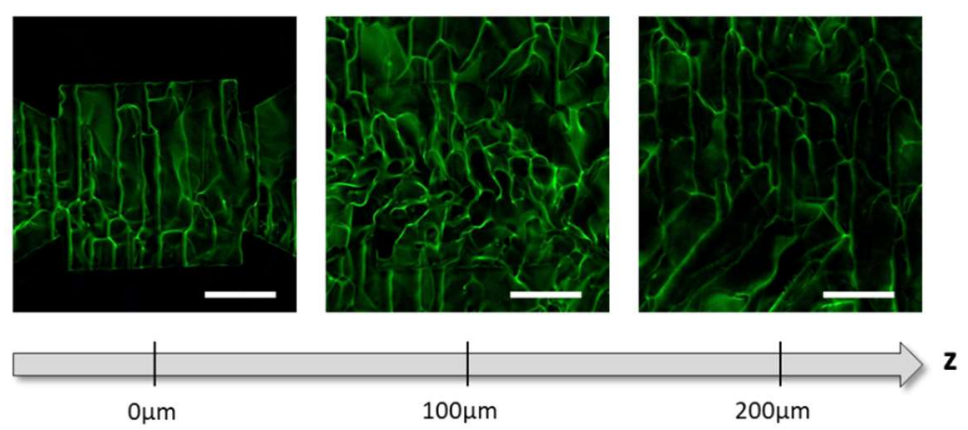

C

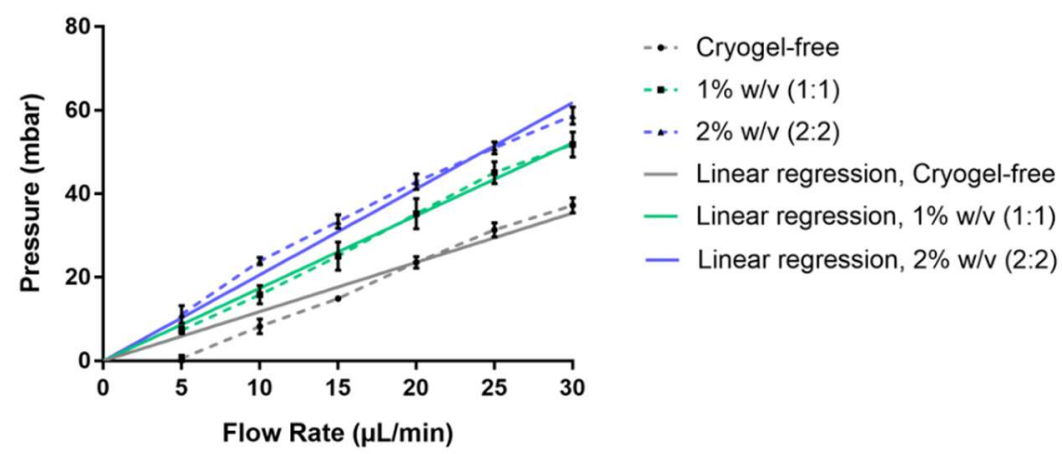

Fig. 5. Microscopic and hydrodynamic characterization of cryogel-integrated biochips. (A) Microscopic observation of cryogel-free and alginate-based cryogel-integrated biochips. Scale bar $=300$ $\mu \mathrm{m}$ (B) Confocal images of fluorescently-labelled 1\% w/v (1:1) alginate-based cryogel-integrated biochips at various depths. (C) Pressure drop characterization of cryogel-free and alginate-based cryogel-integrated biochips $(\mathrm{n}=3)$. Scale bar $=150 \mu \mathrm{m} .(1: 1)$ and $(2: 2)$ represent the AAD:EDC crosslinker ratio.

\subsection{Cell culture within the biochip: viability and functionality}

A total of $0.5 \times 10^{6} \mathrm{HepG} 2 / \mathrm{C} 3 \mathrm{~A}$ cells were seeded on collagen-coated cryogel-free and $1 \%(\mathrm{w} / \mathrm{v})(1: 1)$ alginate-integrated biochips. These cells had a significant proliferation potential as shown in Fig. 6, 
where actin and cell nuclei were stained. Next, cell viability was evaluated with a dead cell staining assay at day 2, 4 and 6 using confocal microscopy (Fig. 6A). The number of dead cells (in red) was negligible from the bottom to the top of the biochip (Fig. S1). Moreover, cell proliferation was monitored between day 2 and 6 . The cells in the cryogel-free biochip were located in 2D in the mid-bottom part whereas the cells in the cryogel-integrated biochip were located in $3 \mathrm{D}$ along the z-axis and throughout of the microfluidic device. Qualitatively, cell proliferation was evaluated by SEM imaging of the device's cross-sections (Fig. 6B). In cryogel-integrated biochips, cells formed a tissue-like 3D structure from the bottom to the top of the biochips with apparent voids corresponding to the cryogel's pores, a prerequisite to allow perfusion. In contrast, cells seeded in cryogel-free biochips proliferated "layer-bylayer" and, unlike cryogel-integrated biochips, they were not able to colonize the space along the z-axis, i.e. between $100 \mu \mathrm{m}$ and $200 \mu \mathrm{m}$. Further, cell density appeared to be lower in the presence of alginate cryogel, but this was most likely due to a "volume effect" as cells were homogeneously distributed throughout the entire space available. 
A
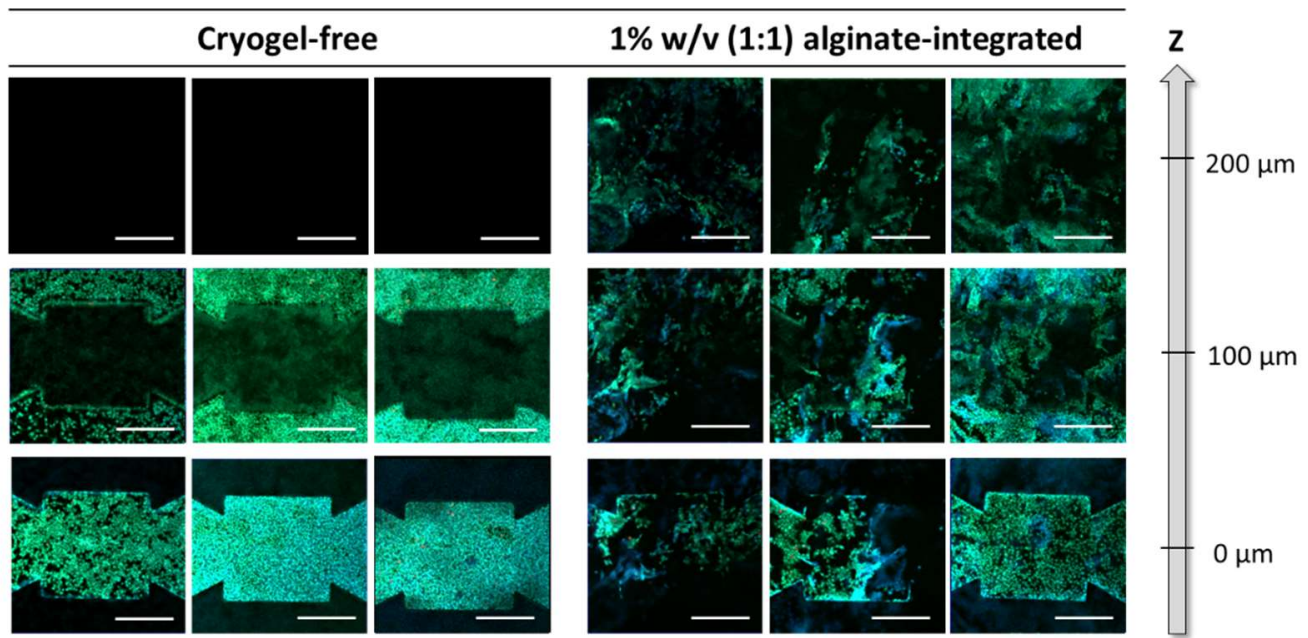

2

4

6

Time (day)

B

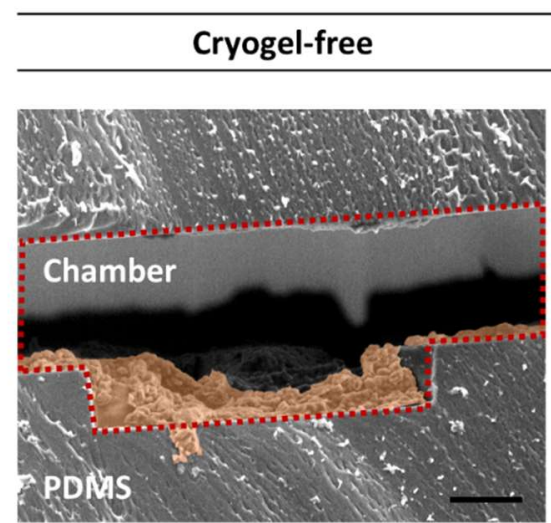
$1 \%$ w/v (1:1) alginate-integrated

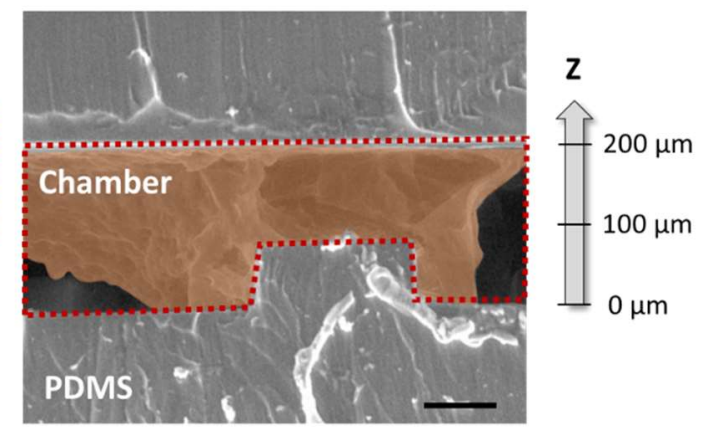

Fig. 6. HepG2/C3A cell culture in cryogel-free and cryogel-integrated biochips. (A) Confocal imaging of cell viability at various time points and depths within the construct. Cell staining: dead cells (red), cytoskeleton (green), and nuclei (blue). Scale bar $=150 \mu \mathrm{m}$. (B) Cross-sectional SEM images of cryogel-free and cryogel-integrated biochips at day 6. In red, cells and alginate. Scale bar $=100 \mu \mathrm{m}$. $(1: 1)$ represents the cross-linker AAD:EDC ratio.

Once the cells proliferated in the device, alginate-based cryogels were dissolved to ensure cells were able to create their own extracellular matrix and as a result, retain a tissue-like cellular organization in 3D. The covalently cross-linked cryogels were degraded enzymatically with alginate lyase through $\beta$ elimination of the glycosidic bond into smaller oligomers. 
Microscopic observations showed that the cells remained in the biochip following cryogel removal (Fig. 7A). Moreover, the 3D cell structures remained nearly intact after the enzymatic treatment and the cells still occupied the space from top to bottom of the biochip device (Fig. 7B).

A

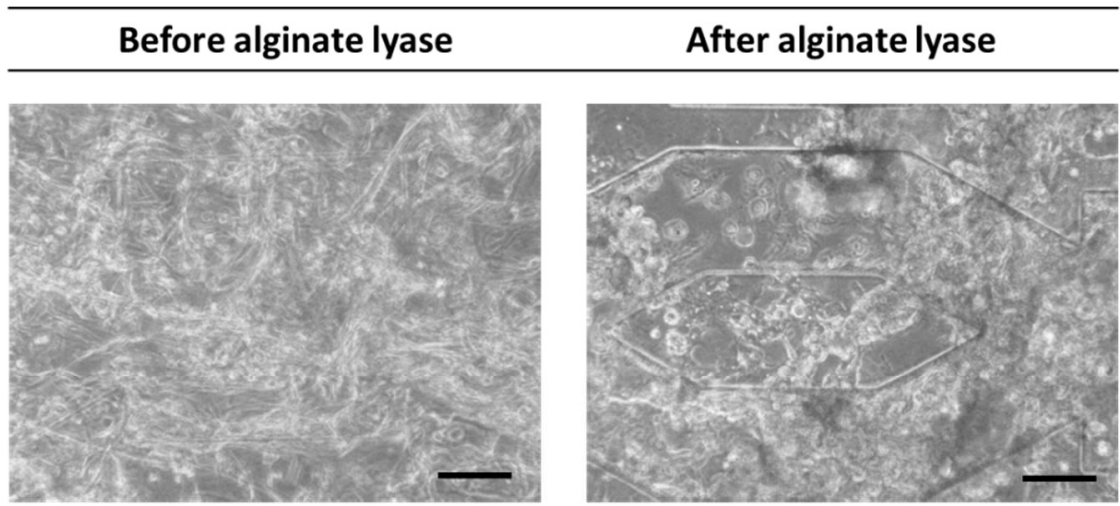

B
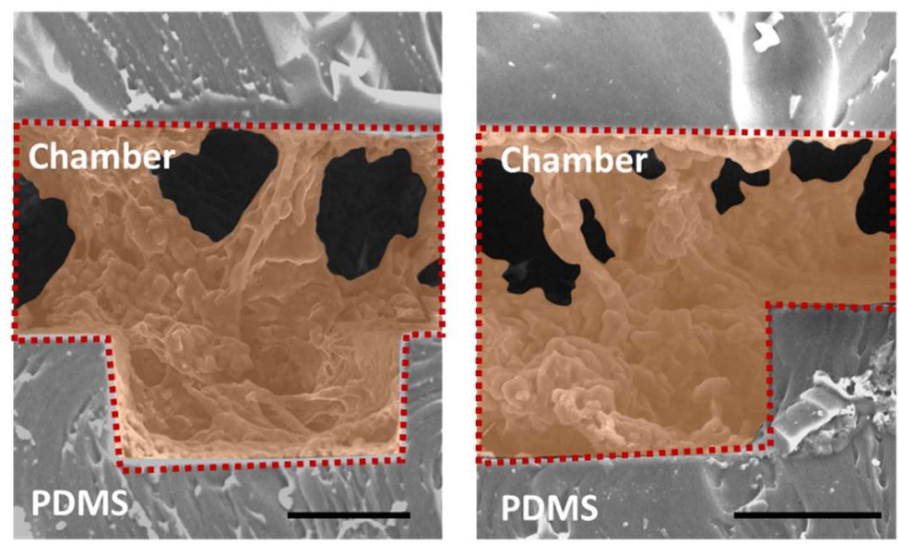

Z

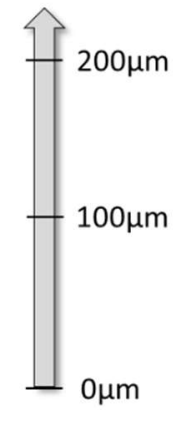

Fig. 7. Cell culture after alginate lyase treatment. (A) Microscopic observation of biochips before and after alginate lyase treatment. (B) Cross-sectional SEM images of cryogel-degraded biochips after alginate lyase treatment. In red, cells. Scale bar $=100 \mu \mathrm{m}$.

Lastly, albumin production was measured to assess HepG2/C3A function. Similarly to cryogel-free biochips, albumin production in $1 \%(\mathrm{w} / \mathrm{v})(1: 1)$ alginate-integrated biochips increased from day 2 to day 6 ranging from $84 \pm 37 \mathrm{ng} / \mathrm{h}$ to $352 \pm 232 \mathrm{ng} / \mathrm{h}$, respectively (Fig. 8A). In the same fashion, glucose consumption increased from day 2 to 6 (Fig. 8B). 
A

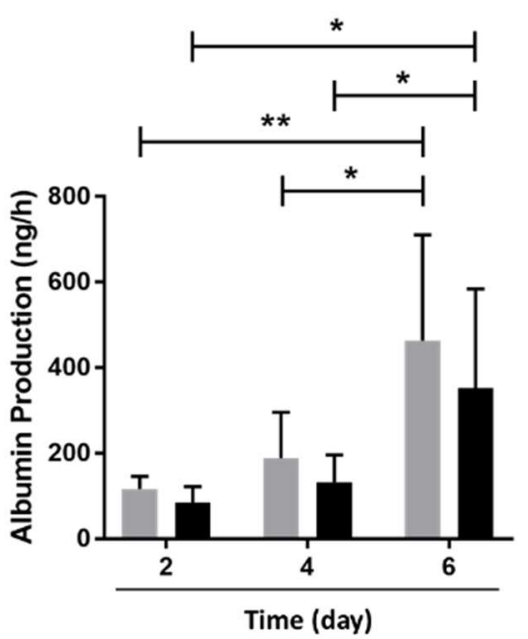

B

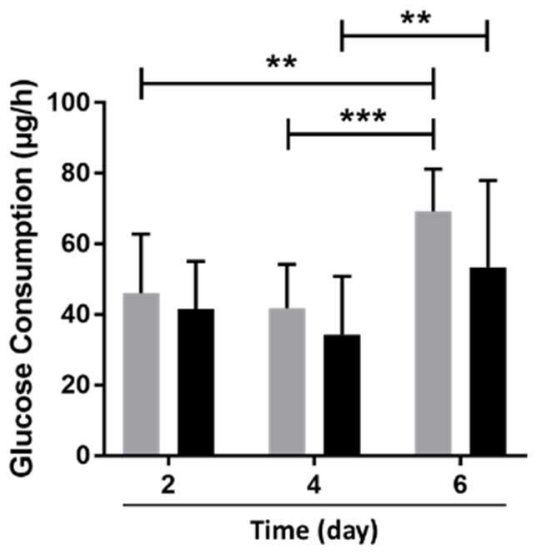

Cryogel-free

$1 \%$ w/v (1:1) alginate-integrated

Fig. 8. Assessment of the physiological functionality of HepG2/C3A. HepG2/C3A cells were cultured in cryogel-free and 1\% w/v (1:1) alginate cryogel-integrated biochips at various time points $(2,4$ and 6 days). (A) Albumin production (B) glucose consumption. Values represent mean and SD ( $\mathrm{n}=4)$. Data were analyzed using two-way ANOVA: ${ }^{*} \mathrm{p}<0,05,{ }^{* *} \mathrm{p}<0,01,{ }^{* * *} \mathrm{p}<0,001$.

\section{Discussion}

Obtaining relevant in vitro liver models remains a key challenge today, specifically in predictive toxicology. The reconstruction of a liver mimicking in vivo conditions is crucial for accurately predicting interactions between the drug and the organ, an essential step in pharmacology. However, the current models still lack reliability, because they do not reproduce the complete set of features necessary for maintaining functional tissue. In recent years, some cell culture approaches have proven to be promising. It has been shown that 3D liver cell cultures improve the toxicological response and make long term culture possible [52,53]. In the same way, it has also been shown that liver cells under flow in microfluidic devices have higher functionalities compared to static cultures $[10,11]$. In order to take advantage of these methods, spheroid-based liver-on-chip models have been developed $[54,55]$. However, the resulted tissue structures remain spheroids whose size are limited due to lack of vascularization and whose shape is restricted to a sphere. Another method is the scaffold-based liveron-chip models but, to our knowledge, few studies have been performed on these devices. In this work, 
we thus developed and characterized a cryogel-integrated biochip as a new 3D cell culture method. This implies meeting specifications such as interconnected macroporous scaffolds, to limit hydraulic resistance, and tunable mechanical properties to emulate healthy or pathological liver tissues.

The cryogel developed here was made by covalent cross-linking of alginate at $-20^{\circ} \mathrm{C}$. By varying the alginate concentration and the cross-linker ratio $\mathrm{AAD}$ :EDC, the mechanical properties of cryogels were tuned: the Young's modulus increased with both parameters, from 1.5 to $29.4 \mathrm{kPa}$. In particular, increasing the amount of EDC had a much greater impact on scaffold stiffness and made it possible to mimic healthy or cirrhotic mechanical properties. Henderson et al. observed the same trends with hyaluronic acid cryogels cross-linked with EDC by varying the $\mathrm{Y}$ from 1 to $10 \mathrm{kPa}$ [56]. To obtain a $\mathrm{Y}$ corresponding to intermediate fibrosis states, other AAD:EDC ratios should be tested, rather than increasing the alginate concentration over $2 \%$ because of high viscosity solution. Moreover, fibrosis being a complex state, in addition to rigidity, it would be interesting to bring to the model other characteristics such as the culture of stellate cells.

Both parameters, alginate concentration and AAD:EDC ratio, also affected the swelling ratio of the cryogels. It tended to decrease with increasing alginate concentration and EDC amount. Similar results were observed with previously reported hyaluronic acid cryogels: the more densely cross-linked scaffolds showed less swelling, in the same way as more concentrated polymer scaffolds [56].

At the microscopic level, it seems that the porosity was reduced at cross-linker ratios of (1:2) and (1:3), whereas an interconnected porous structure was observed for $1 \%$ and $2 \%(\mathrm{w} / \mathrm{v})$ alginate cryogels. These porous scaffolds had a pore size of approximately $100 \mu \mathrm{m}$, which was large enough to allow fluid flow and enable cell colonization. These types of scaffold correspond to those commonly used for 3D static cell cultures in liver tissue engineering. Tripathi et al. synthesized an agarose-chitosan scaffold at subzero temperatures. Its pore size was in the range of 10 to $120 \mu \mathrm{m}$ [57]. Similarly, Glicklis et al. developed physically cross-linked alginate sponges using a freeze-drying method that displayed a highly porous structure with interconnected pores and pore sizes ranging from 100 to $150 \mu \mathrm{m}$ [58]. Therefore, based on our results, the $1 \%$ and $2 \%$ alginate cryogels were selected for further studies. These scaffolds mimic healthy liver stiffness. In order to emulate the stiffness of the different degrees of fibrosis while maintaining a porous structure, a balance between alginate concentration and AAD:EDC ratio needs to 
be found. Another possibility could be the combination between two polymers, such as alginate with agarose, a polymer forming rigid structures [39].

After characterizing and selecting the cryogels, they were integrated into the biochip. The cryogels completely filled the biochip, from the outlet to the inlet and from the bottom to the top. The presence of the cryogel in the biochip added a resistance to flow that was characterized between 10 to $30 \mu \mathrm{L} / \mathrm{min}$, i.e. working flow rates. In particular, increasing alginate concentration increased the flow resistance of the cryogel. Tripathi et al. obtained similar results: cryogel permeability decreased as the polymer concentration increased [39]. Although the resistance to flow remained acceptable for both $1 \%$ and $2 \%$ alginate cryogels, we chose the lowest polymer concentration, i.e. $1 \%$ alginate, for the cell culture study. This choice was also motivated because the resistance to flow is expected to increase with cell proliferation, phenomenon that should be quantified in future studies.

We succeeded in keeping HepG2/C3A viable, proliferative, and functional for 6 days in perfusion in the cryogel-integrated biochips, while the cryogel-free biochips being considered as controls. HepG2/C3A cells cultured in the $1 \%(\mathrm{w} / \mathrm{v})(1: 1)$ alginate-integrated biochip demonstrated functionality similar to the cells cultured in the cryogel-free biochip. Moreover, in the cryogel-integrated biochips, they spread all over the 3D alginate structure made available by the presence of very large pores, whereas in the cryogelfree biochips, they grew mostly on the collagen-coated PDMS microstructures, leading to a "semi-3D" organization. The 3D cell structures remained stable after alginate lyase treatment. To the best of our knowledge, no structures like the ones observed in the cryogel-integrated biochip have been described yet. Unlike the perfused microsystems reported in 2D as monolayers [59], semi 3D [48] or in 3D as spheroids [54], this device should allow diffusion through the cell culture thanks to the interconnected pores that make perfusion possible even after cell colonization on the lining of the scaffold.

Although this cryogel-integrated biochip showed promising results with the cell line HepG2/C3A, culture of primary hepatocytes needs to be performed to evaluate the efficiency of this new device on hepatic activities, in particular the xenobiotic activities. To go further in the development of an in vitro liver model, the sinusoid structure could be reproduced. To do so, the 3D cell structure formed by the hepatic cells could be coated with molecules from the ECM before seeding liver sinusoidal endothelial cells, thus reproducing the space of Disse and the capillaries. Beyond the liver, this cryogel-integrated 
biochip represents a new cell culture system, in a 3D and dynamic environment, and could be adapted to other cell types and therefore other organs.

\section{Conclusion}

In this study, we successfully designed a cryogel-integrated biochip for liver tissue engineering. This new cell culture device, combining a 3D microenvironment and perfusable cell culture, mimics more closely the native liver microenvironment by reconstructing its physiological stiffness. The feasibility study performed here with HepG2/C3A showed viable and functional cells up to 6 days of culture, as well enabling 3D tissue organization throughout the biochip. This device is a promising tool for potentially developing reliable in vitro liver microtissues for drug toxicity and efficacy studies, but also may be a platform to better understand and dissect liver cell biology since the mechanical properties of healthy or pathological liver tissues could be recapitulated.

\section{Author Contributions}

Lilandra Boulais : methodology, formal analysis, investigation, writing—original draft preparation Rachid Jellali : methodology, formal analysis, investigation

Ulysse Pereira and Eric Leclerc: methodology

Sidi A. Bencherif and Cécile Legallais : conceptualization, supervision, writing—review and editing

All authors have read and agreed to the published version of the manuscript.

\section{Funding}

This work was supported by the "Comité de l'Oise de la Ligue contre le cancer", PIA-RHU iLite [ANR 16-RHUS-0005], the FACE Foundation [711R] and the National Science Foundation [DMR 1847843].

\section{Data Availability Statement}

Raw data are stored in-house at UTC and can be made available upon request. 


\section{Acknowledgements}

The authors thank Darlène Teyssot, Anna Sebbagh, Margaux Broussard and Solène Rousseau for their technical assistance, Frédéric Nadaud for his help with SEM imaging, Caroline Lefebvre for her help with confocal microscopy imaging, and Yannick Rossez for kindly allowing us to use the lyophilizer.

\section{Conflict of Interest}

The authors declare no conflict of interest. The funders had no role in the design of the study; in the collection, analyses, or interpretation of data; in the writing of the manuscript, or in the decision to publish the results.

\section{References}

[1] D. Cook, D. Brown, R. Alexander, R. March, P. Morgan, G. Satterthwaite, M.N. Pangalos, Lessons learned from the fate of AstraZeneca's drug pipeline: A five-dimensional framework, Nat. Rev. Drug Discov. 13 (2014) 419-431. https://doi.org/10.1038/nrd4309.

[2] M.D. Rawlins, Cutting the cost of drug development?, Nat. Rev. Drug Discov. 3 (2004) 360364. https://doi.org/10.1038/nrd1347.

[3] R. Saxena, N.D. Theise, J.M. Crawford, Microanatomy of the human liver - Exploring the hidden interfaces, Hepatology. 30 (1999) 1339-1346. https://doi.org/10.1002/hep.510300607.

[4] J. Carvalho, P. Carvalho, D. Gomes, A. Goes, Innovative Strategies for Tissue Engineering, Adv. Biomater. Sci. Biomed. Appl. (2013) 295-313. https://doi.org/10.5772/53337.

[5] N.K. Inamdar, J.T. Borenstein, Microfluidic cell culture models for tissue engineering, Curr. Opin. Biotechnol. 22 (2011) 681-689. https://doi.org/10.1016/j.copbio.2011.05.512.

[6] S.N. Bhatia, D.E. Ingber, Microfluidic organs-on-chips, Nat. Biotechnol. 32 (2014) 760-772. https://doi.org/10.1038/nbt.2989.

[7] M.C. Carletti E., Motta A., Scaffolds for Tissue Engineering and 3D Cell Culture, in: 3D Cell Cult., Haycock J., 2011.

[8] R.I. Soldatow VY, Lecluyse EL, Griffith LG, In vitro models for liver toxicity testing, Toxicol Res. 2 (2014) 23-39. https://doi.org/10.1039/C2TX20051A.In. 
[9] J. Lee, K. Ho, S. Fan, Liver microsystems in vitro for drug response, J. Biomed. Sci. 26 (2019). https://doi.org/10.1186/s12929-019-0575-0.

[10] L. Xia, S. Ng, R. Han, X. Tuo, G. Xiao, H.L. Leo, T. Cheng, H. Yu, Laminar-flow immediateoverlay hepatocyte sandwich perfusion system for drug hepatotoxicity testing, Biomaterials. 30 (2009) 5927-5936. https://doi.org/10.1016/j.biomaterials.2009.07.022.

[11] Y.C. Toh, T.C. Lim, D. Tai, G. Xiao, D. Van Noort, H. Yu, A microfluidic 3D hepatocyte chip for drug toxicity testing, Lab Chip. 9 (2009) 2026-2035. https://doi.org/10.1039/b900912d.

[12] J. Kim, S.A. Bencherif, W.A. Li, D.J. Mooney, Cell-friendly inverse opal-like hydrogels for a spatially separated co-culture system, Macromol. Rapid Commun. 35 (2014) 1578-1586. https://doi.org/10.1002/marc.201400278.

[13] J.E. Prata, T.A. Barth, S.A. Bencherif, N.R. Washburn, Complex fluids based on methacrylated hyaluronic acid, Biomacromolecules. 11 (2010) 769-775. https://doi.org/10.1021/bm901373x.

[14] A.S. Hoffman, Hydrogels for biomedical applications, Adv. Drug Deliv. 54 (2002) 3-12. https://doi.org/10.1016/j.addr.2012.09.010.

[15] J.L. Drury, D.J. Mooney, Hydrogels for tissue engineering: Scaffold design variables and applications, Biomaterials. 24 (2003) 4337-4351. https://doi.org/10.1016/S01429612(03)00340-5.

[16] O. Gsib, J.L. Duval, M. Goczkowski, M. Deneufchatel, O. Fichet, V. Larreta-Garde, S.A. Bencherif, C. Egles, Evaluation of fibrin-based interpenetrating polymer networks as potential biomaterials for tissue engineering, Nanomaterials. 7 (2017) 1-21. https://doi.org/10.3390/nano7120436.

[17] S.A. Bencherif, T.M. Braschler, P. Renaud, Advances in the design of macroporous polymer scaffolds for potential applications in dentistry, J. Periodontal Implant Sci. 43 (2013) 251-261. https://doi.org/10.5051/jpis.2013.43.6.251.

[18] O. Gsib, L.J. Eggermont, C. Egles, S.A. Bencherif, Engineering a macroporous fibrin-based sequential interpenetrating polymer network for dermal tissue engineering, Biomater. Sci. (2020). https://doi.org/10.1039/D0BM01161D.

[19] Z.J. Rogers, M.P. Zeevi, R. Koppes, S.A. Bencherif, Electroconductive Hydrogels for Tissue 
Engineering: Current Status and Future Perspectives, Bioelectricity. 2 (2020) 279-292. https://doi.org/10.1089/bioe.2020.0025.

[20] A. Amirsadeghi, A. Jafari, L.J. Eggermont, S.-S. Hashemi, S.A. Bencherif, M. Khorram, Vascularization strategies for skin tissue engineering, Biomater. Sci. 8 (2020) 4073-4094. https://doi.org/10.1039/D0BM00266F.

[21] S.A. Bencherif, A. Srinivasan, J.A. Sheehan, L.M. Walker, C. Gayathri, R. Gil, J.O. Hollinger, K. Matyjaszewski, N.R. Washburn, End-group effects on the properties of PEG-co-PGA hydrogels, Acta Biomater. 5 (2009) 1872-1883. https://doi.org/https://doi.org/10.1016/j.actbio.2009.02.030.

[22] S.A. Bencherif, J.A. Sheehan, J.O. Hollinger, L.M. Walker, K. Matyjaszewski, N.R. Washburn, Influence of cross-linker chemistry on release kinetics of PEG-co-PGA hydrogels, J. Biomed. Mater. Res. Part A. 90A (2009) 142-153. https://doi.org/https://doi.org/10.1002/jbm.a.32069.

[23] K. Joshi Navare, L.J. Eggermont, Z.J. Rogers, H.S. Mohammed, T. Colombani, S.A. Bencherif, Antimicrobial Hydrogels: Key Considerations and Engineering Strategies for Biomedical Applications BT - Racing for the Surface: Pathogenesis of Implant Infection and Advanced Antimicrobial Strategies, in: B. Li, T.F. Moriarty, T. Webster, M. Xing (Eds.), Springer International Publishing, Cham, 2020: pp. 511-542. https://doi.org/10.1007/978-3030-34475-7_22.

[24] S.A. Bencherif, N.R. Washburn, K. Matyjaszewski, Synthesis by AGET ATRP of Degradable Nanogel Precursors for In Situ Formation of Nanostructured Hyaluronic Acid Hydrogel, Biomacromolecules. 10 (2009) 2499-2507. https://doi.org/10.1021/bm9004639.

[25] S.A. Bencherif, R. Warren Sands, O.A. Ali, W.A. Li, S.A. Lewin, T.M. Braschler, T.-Y. Shih, C.S. Verbeke, D. Bhatta, G. Dranoff, D.J. Mooney, Injectable cryogel-based whole-cell cancer vaccines, Nat. Commun. 6 (2015) 7556. https://doi.org/10.1038/ncomms8556.

[26] S. Kennedy, S. Bencherif, D. Norton, L. Weinstock, M. Mehta, D. Mooney, Rapid and Extensive Collapse from Electrically Responsive Macroporous Hydrogels, Adv. Healthc. Mater. 3 (2014) 500-507. https://doi.org/https://doi.org/10.1002/adhm.201300260.

[27] A. Memic, M. Rezaeeyazdi, P. Villard, Z.J. Rogers, T. Abudula, T. Colombani, S.A. Bencherif, 
Effect of Polymer Concentration on Autoclaved Cryogel Properties, Macromol. Mater. Eng. 305 (2020) 1900824. https://doi.org/https://doi.org/10.1002/mame.201900824.

[28] T. Colombani, L.J. Eggermont, S.M. Hatfield, M. Rezaeeyazdi, A. Memic, M. V Sitkovsky, S.A. Bencherif, Oxygen-generating cryogels restore T cell-mediated cytotoxicity in hypoxic tumors, BioRxiv. (2020) 2020.10.08.329805. https://doi.org/10.1101/2020.10.08.329805.

[29] T. He, B. Li, T. Colombani, K. Joshi-Navare, S. Mehta, J. Kisiday, S.A. BENCHERIF, A.G. Bajpayee, Hyaluronic acid-based shape-memory cryogel scaffolds for focal cartilage defect repair, Tissue Eng. Part A. (2020). https://doi.org/10.1089/ten.TEA.2020.0264.

[30] T. Abudula, K. Bhatt, L.J. Eggermont, N. O'Hare, A. Memic, S.A. Bencherif, Supramolecular Self-Assembled Peptide-Based Vaccines: Current State and Future Perspectives, Front. Chem. 8 (2020). https://doi.org/10.3389/fchem.2020.598160.

[31] K. Joshi Navare, T. Colombani, M. Rezaeeyazdi, N. Bassous, D. Rana, T. Webster, A. Memic, S.A. Bencherif, Needle-injectable microcomposite cryogel scaffolds with antimicrobial properties, Sci. Rep. 10 (2020) 18370. https://doi.org/10.1038/s41598-020-75196-1.

[32] Z.J. Rogers, S.A. Bencherif, Cryogelation and cryogels, Gels. 5 (2019) 6-7. https://doi.org/10.3390/gels5040046.

[33] P. Villard, M. Rezaeeyazdi, T. Colombani, K. Joshi-Navare, D. Rana, A. Memic, S.A. Bencherif, Autoclavable and Injectable Cryogels for Biomedical Applications, Adv. Healthc. Mater. 8 (2019) 1900679. https://doi.org/https://doi.org/10.1002/adhm.201900679.

[34] M.-E. Han, S.-H. Kim, H.D. Kim, H.-G. Yim, S.A. Bencherif, T.-I. Kim, N.S. Hwang, Extracellular matrix-based cryogels for cartilage tissue engineering, Int. J. Biol. Macromol. 93 (2016) 1410-1419. https://doi.org/https://doi.org/10.1016/j.ijbiomac.2016.05.024.

[35] T.-Y. Shih, S.O. Blacklow, A.W. Li, B.R. Freedman, S. Bencherif, S.T. Koshy, M.C. Darnell, D.J. Mooney, Injectable, Tough Alginate Cryogels as Cancer Vaccines, Adv. Healthc. Mater. 7 (2018) 1701469. https://doi.org/https://doi.org/10.1002/adhm.201701469.

[36] A. Memic, T. Colombani, L.J. Eggermont, M. Rezaeeyazdi, J. Steingold, Z.J. Rogers, K.J. Navare, H.S. Mohammed, S.A. Bencherif, Latest Advances in Cryogel Technology for Biomedical Applications, Adv. Ther. 1800114 (2019) 1-45. 
https://doi.org/10.1002/adtp.201800114.

[37] S.A. Bencherif, R.W. Sands, D. Bhatta, P. Arany, C.S. Verbeke, D. a Edwards, D.J. Mooney, Injectable preformed scaffolds with shape-memory properties., Proc. Natl. Acad. Sci. U. S. A. 109 (2012) 19590-5. https://doi.org/10.1073/pnas.1211516109.

[38] V.. Lozinsky, Polymeric cryogels as a new family of macroporous and supermacroporous materials for biotechnological purposes, Russ Chem Bull. 57 (2008) 1015-1032.

[39] A. Tripathi, A. Kumar, Multi-Featured Macroporous Agarose - Alginate Cryogel : Synthesis and Characterization for Bioengineering Applications, Macromolecular. (2011) 22-35. https://doi.org/10.1002/mabi.201000286.

[40] M. Rezaeeyazdi, T. Colombani, A. Memic, S.A. Bencherif, Injectable hyaluronic acid-cogelatin cryogels for tissue-engineering applications, Materials (Basel). 11 (2018) 23-25. https://doi.org/10.3390/ma11081374.

[41] L.J. Eggermont, Z.J. Rogers, T. Colombani, A. Memic, S.A. Bencherif, Injectable Cryogels for Biomedical Applications, Trends Biotechnol. 38 (2020) 418-431. https://doi.org/10.1016/j.tibtech.2019.09.008.

[42] F.M. Plieva, I.Y. Galaev, W. Noppe, B. Mattiasson, Cryogel applications in microbiology, Trends Microbiol. (2008) 543-551. https://doi.org/10.1016/j.tim.2008.08.005.

[43] V.I. Lozinsky, I.Y. Galaev, F.M. Plieva, I.N. Savina, H. Jungvid, B. Mattiasson, Polymeric cryogels as promising materials of biotechnological interest, Trends Biotechnol. 21 (2003) 445-451. https://doi.org/10.1016/j.tibtech.2003.08.002.

[44] D. Haylock, A.J.O. Connor, Cryogels for Biomedical Applications, J. Mater. Chem. 1 (2013) 2682-2695. https://doi.org/10.1039/C3TB20280A.

[45] W.E. Hennink, C.F. van Nostrum, Novel crosslinking methods to design hydrogels, Adv. Drug Deliv. Rev. 64 (2012) 223-236. https://doi.org/10.1016/j.addr.2012.09.009.

[46] G. Orive, A.M. Carcaboso, R.M. Hernández, A.R. Gascón, J.L. Pedraz, Biocompatibility Evaluation of Different Alginates and Alginate-Based Microcapsules, Biomacromolecules. 6 (2005) 927-931. https://doi.org/10.1021/bm049380x.

[47] K.Y. Lee, D.J. Mooney, Alginate: Properties and biomedical applications, Prog. Polym. Sci. 37 
(2012) 106-126. https://doi.org/10.1016/j.progpolymsci.2011.06.003.

[48] R. Baudoin, L. Griscom, J.M. Prot, C. Legallais, E. Leclerc, Behavior of HepG2/C3A cell cultures in a microfluidic bioreactor, Biochem. Eng. J. 53 (2011) 172-181. https://doi.org/10.1016/j.bej.2010.10.007.

[49] R. Jellali, P. Paullier, M. Fleury, E. Leclerc, Liver and kidney cells cultures in a new perfluoropolyether biochip, Sensors Actuators B. Chem. 229 (2016) 396-407. https://doi.org/10.1016/j.snb.2016.01.141.

[50] R. Baudoin, G. Alberto, P. Paullier, C. Legallais, E. Leclerc, Parallelized microfluidic biochips in multi well plate applied to liver tissue engineering, Sensors Actuators, B Chem. 173 (2012) 919-926. https://doi.org/10.1016/j.snb.2012.06.050.

[51] R. Baudoin, G. Alberto, A. Legendre, P. Paullier, M. Naudot, M.J. Fleury, S. Jacques, L. Griscom, E. Leclerc, Investigation of expression and activity levels of primary rat hepatocyte detoxication genes under various flow rates and cell densities in microfluidic biochips, Biotechnol. Prog. 30 (2014) 401-410. https://doi.org/10.1002/btpr.1857.

[52] S.C. Ramaiahgari, M.W. den Braver, B. Herpers, V. Terpstra, J.N.M. Commandeur, B. Van De Water, L.S. Price, A 3D in vitro model of differentiated HepG2 cell spheroids with improved liver - like properties for repeated dose high - throughput toxicity studies, Arch Toxicol. (2014) 1083-1095. https://doi.org/10.1007/s00204-014-1215-9.

[53] M. Bhattacharya, M.M. Malinen, P. Lauren, Y.R. Lou, S.W. Kuisma, L. Kanninen, M. Lille, A. Corlu, C. Guguen-Guillouzo, O. Ikkala, A. Laukkanen, A. Urtti, M. Yliperttula, Nanofibrillar cellulose hydrogel promotes three-dimensional liver cell culture, J. Control. Release. 164 (2012) 291-298. https://doi.org/10.1016/j.jconrel.2012.06.039.

[54] S.A. Lee, D.Y. No, E. Kang, J. Ju, D.S. Kim, S.H. Lee, Spheroid-based three-dimensional liver-on-a-chip to investigate hepatocyte-hepatic stellate cell interactions and flow effects, Lab Chip. 13 (2013) 3529-3537. https://doi.org/10.1039/c31c50197c.

[55] S. Bauer, C. Wennberg Huldt, K.P. Kanebratt, I. Durieux, D. Gunne, S. Andersson, L. Ewart, W.G. Haynes, I. Maschmeyer, A. Winter, C. Ämmälä, U. Marx, T.B. Andersson, Functional coupling of human pancreatic islets and liver spheroids on-a-chip: Towards a novel human ex 
vivo type 2 diabetes model, Sci. Rep. 7 (2017) 1-11. https://doi.org/10.1038/s41598-01714815-w.

[56] T.M.A. Henderson, K. Ladewig, D.N. Haylock, K.M. McLean, A.J. OConnor, Formation and characterisation of a modifiable soft macro-porous hyaluronic acid cryogel platform, J. Biomater. Sci. Polym. Ed. 26 (2015) 881-897. https://doi.org/10.1080/09205063.2015.1065597.

[57] A. Tripathi, J.S. Melo, Preparation of a sponge-like biocomposite agarose - chitosan sca ff old with primary hepatocytes for establishing an in vitro 3D liver tissue model, RSC Adv. (2015) 30701-30710. https://doi.org/10.1039/c5ra04153h.

[58] R. Glicklis, L. Shapiro, R. Agbaria, J.C. Merchuk, S. Cohen, Hepatocyte behavior within threedimensional porous alginate scaffolds, Biotechnol. Bioeng. 67 (2000) 344-353. https://doi.org/10.1002/(SICI)1097-0290(20000205)67:3<344::AID-BIT11>3.0.CO;2-2.

[59] B.J. Kane, M.J. Zinner, M.L. Yarmush, M. Toner, Liver-Specific Functional Studies in a Microfluidic Array of Primary Mammalian Hepatocytes, Anal. Chem. 78 (2006) 4291-4298. https://doi.org/10.1021/ac051856v. 